\title{
General Medical Practitioners Need to Be Aware of the Theories on Which Our Work Depends
}

Paul Thomas, FRCGP, MD

Centre for Study of Policy and Practice in Health and Social Care, Thames Valley University, Ealing, London
Conflict of interest: none reported

\section{CORRESPONDING AUTHOR}

Paul Thomas, FRCGP, MD

Westel House

32-38 Uxbridge Rd

Ealing, London W5 2BS, UK

Paul.Thomas@tvu.ac.uk

\begin{abstract}
When general practitioners and family physicians listen, reflect, and diagnose, we use 3 different theories of knowledge. This essay explores these theories to highlight an approach to clinical practice, inquiry, and learning that can do justice to the complex and uncertain world we experience. The following points are made: (1) A variety of approaches to research and audit are needed to illuminate the richness of experience witnessed by general medical practitioners. (2) Evidence about the past cannot predict the future except in simple, short-term, or slowly changing situations. (3) We consciously or unconsciously weave together evidence generated through 3 fundamental theories of knowledge, termed postpositivism, critical theory, and constructivism, to make sense of everyday experience. We call it listening, reflecting, and diagnosing. (4) These 3 fundamental theories of knowledge highlight different aspects within a world that is more complex, integrated, and changing than any single theory can reveal on its own; they frame what we see and how we act in everyday situations. (5) Moving appropriately between these different theories helps us to see a fuller picture and provides a framework for improving our skills as clinicians, researchers, and learners. (6) Narrative unity offers a way to bring together different kinds of evidence to understand the overall health of patients and of communities; evidence of all kinds provides discrete snapshots of more complex stories in evolution. (7) We need to understand these issues so we can create an agenda for clinical practice, inquiry, and learning appropriate to our discipline.
\end{abstract}

Ann Fam Med 2006;4:450-454. DOI: 10.1370/afm.581.

\section{INTRODUCTION}

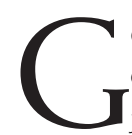

ood general medical practice should be based on evidence whenever appropriate and possible, but what form of evidence can do justice to the multifaceted world I encounter as a general practitioner/family physician? First, I share with specialists a need for objective evidence about harm to patients from known conditions-asthma, bedwetting, cancer, debt (and all conditions beginning with the other letters of the alphabet). Second, I need to generate evidence about hidden and interconnected things in patients' lives, such as loss of purpose or relationship difficulties. Finally, I need to bring together a diversity of objective and subjective evidence to develop with a patient a unique plan that will improve more than one thing at the same time.

Evidence is knowledge generated from competent inquiry. Evidence, however, is commonly associated with a particular approach to inquiry called positivism (quantitative research). Inquiry helps me with the first of my 3 needs when I need objective evidence about known diseases in simple, controlled situations. It is less reliable, however, in complex and changing situations. ${ }^{1-3}$ 
An image that reveals the limitations of positivism is a game of billiards. Each ball has weight and shape that does not change during the game. When one ball hits another, it causes movement that is predictable because everything else stays still, which is the definition of a controlled laboratory. The world experienced by general medical practitioners, however, often lacks such simplicity and predictability. Patients, unlike billiard balls, are undergoing constant change internally, and externally so are their contexts (relationships, jobs, organizations, projects). Consider the complexity of the task that would face a billiard player if the properties and trajectories of the balls and the table were all changing simultaneously.

Simplicity and predictability do not make positivism wrong, they merely limit it. On its own, positivism can lead to overly simplistic ideas that prevent us from realizing our potential to heal or harm people. To understand what generalists must do in less straightforward situations, we must develop an approach that goes beyond positivistic assumptions about the world.

In this essay I wish to argue that the complex, uncertain, and creative aspects of the role of a generalist medical practitioner can be understood by complementing positivist theory of knowledge with 2 other respected and equally important theories termed critical theory and constructivism. ${ }^{4}$ Using all 3 theories in clinical practice requires complementing diagnosing with listening and reflection. In research and audit it requires complementing quantitative inquiry with exploratory and participatory approaches.

I want to go further. I want to argue that you will already know and practice these approaches, but you may lack the language to talk about it and consequently be held back from improving your skills. In the Englishspeaking world philosophy is rarely part of a medical student curriculum. As a result, theory of knowledge is considered by many to be irrelevant. I want to argue the opposite-it provides language to explain the essence of generalist practice that is usually described as a mystery. ${ }^{5}$

\section{Positivism, Critical Theory, and Constructivism}

To distinguish their unique features, I describe in this section the assumptions made by positivism, critical theory, and constructivism about the nature of reality and the generation of knowledge. I then argue that each of these 3 approaches offers equal but different insights into the complex evolving stories that patients tell us. Finally, I suggest how general medical practice can improve its use of all 3 theories in combination.

\section{Positivism}

Positivism expects the world to be ordered simply and to be predictable. Entities really exist, unchanging and irrespective of other things. This assumption is called a

\begin{tabular}{l}
$\begin{array}{l}\text { Table 1. Definitions of Ontology, Epistemology, } \\
\text { and Methodology }\end{array}$ \\
\hline Ontology \\
$\begin{array}{c}\text { Ontology is concerned with the assumptions } \\
\text { made by different beliefs about reality.,6 I am } \\
\text { asking an ontological question when I ask, } \\
\text { "In what ways is something really there?" If I } \\
\text { believe that a stone has a discrete, enduring } \\
\text { existence separate from everything else, and } \\
\text { a smile has a transient existence that marks a } \\
\text { meaningful transaction between people, I am } \\
\text { making an ontological distinction. } \\
\text { Epistemology seeks to define knowledge within a } \\
\text { particular belief about reality. I am asking an } \\
\text { epistemological question when I ask, "What is } \\
\text { the relationship between the knower and the } \\
\text { known?"4 If I believe that a patient can subjec- } \\
\text { tively experience the effect of a drug differ- } \\
\text { ently from a claim made by scientific evidence, } \\
\text { I am making an epistemological distinction. } \\
\text { Methodology is the study of ways of knowing } \\
\text { within a particular belief about reality. }{ }^{6} \text { I am } \\
\text { asking a methodological question when I ask, } \\
\text { "What approach to knowledge generation will } \\
\text { provide a reliable answer to my question?" I } \\
\text { make different methodological choices when } \\
\text { I invite respondents to (1) score a pick-list of } \\
\text { options, (2) speak in their own words, or (3) } \\
\text { participate in a focus group. }\end{array}$ \\
Methodology
\end{tabular}

critical $^{*}$ realist ontology ${ }^{4}$ (Table 1 displays definitions of ontology, epistemology, and methodology). Truth is like a nugget of gold waiting to be recognized. I know it is there because tests detect its objective presence (its epistemology is dualist-objectivist). Its methodology is experimental-manipulative- "a question or hypothesis is stated in advance in propositional form and subjected to empirical tests under controlled conditions." ${ }^{\prime 4}$ This approach uses research methods, such as experiments, in which features of interest are named in advance, measured, and counted. Validity requires a statistical difference between these numbers. This theory has no power to reveal context (discrete features are counted in isolation from other things), and no power to reveal novelty (things must be named in advance).

The French philosopher Auguste Comte coined the term positivism in the 19th century. It was a reaction against the theological and metaphysical understandings of knowledge that predated it. These previous understandings considered that truth was too complex and interconnected to be understood by mere mortals-personal struggle and contemplation guided by priests would reveal the best next steps in a world that was ultimately unknowable.

The new science was empowering, allowing people to predict what would happen in simple situations. For example, travelers can trust the structural integrity of airplanes, and doctors can know what forms of treat-

* The word critical distinguishes postpositivism from traditional positivism that held the naïve view that what was seen was the whole truth. Postpositivists accept that the world is more complex than superficial insights reveal. 
ment are better at curing named diseases. The weakness of this type of knowledge is that it cannot reliably interpret interdependent and coevolving phenomena.

Take the example of depression. Although evidence from positivist inquiry helps me to recognize the features of depression and consider a range of reliable treatment options, as a generalist, I know that depression is not one entity. It is a feeling that arises from multiple coincidental and interacting factors. Inside depression can be found personal inadequacy, unresolved past hurts, physical disease, bullying at work, genetic predisposition, dysfunctional families, and many other things, all compounding and causing each other. By helping patients to bring into view the range of factors that contribute to their depression, I can help them to help themselves. When I help patients in this way, they often say as they leave: "You know-I feel better just from having come."

When I explore these issues with a patient, I am considering the diagnosis of depression, not as the end of the matter, but the start of an exploration of something complex. Multiple factors are constantly affecting each other and adapting to changes in each other. The best plan includes a set of complementary actions to reduce harm and increase healthy ones. Positivism obstructs this exploration of complexity because it reduces rather than expands the horizon of inquiry. This reductionist tendency of positivism provoked researchers to develop exploratory and participatory approaches to inquiry that became known as qualitative research. Qualitative research was originally defined as anything that was not quantitative (positivist). In time researchers came to agree that qualitative research includes both critical theory and constructivism, which together can generate knowledge about contexts and innovation that are invisible to positivism.

\section{Critical Theory}

The theory of knowledge that best reveals the context of a phenomenon is called critical (social) theory or "ideologically oriented inquiry." As with positivism its ontology is critical realist - truth is still expected to be really there but hidden by more superficial or transient truths. The researcher considers different perspectives and meanings that are not immediately obvious. Its epistemology is subjectivist in that critical theory values what people know from experience. Its methodology is dialogic_-people of different perspectives debate the rights and wrongs of different versions of the truth to remove false consciousness and arrive at a better version of the truth. This approach uses research methods, such as case studies that "focus on a contemporary phenomenon within some real-life context."7 Validity requires concordance between different perceptions (termed triangulation) that pinpoints the so-called real truth.
The origins of critical theory are attributed to the German philosopher Jurgen Habermas, who maintained that our understandings of the world are distorted because we are blind to much of what is relevant. ${ }^{8}$ Contemporary application of critical theory is "concerned in particular with issues of power and justice and the ways that the economy, matters of race, class and gender, ideologies, discourses, education, religion and other social institutions, and cultural dynamics interact to construct a social system." ${ }^{\prime 9}$

\section{Constructivism}

Novelty and innovation are best understood through the theory of knowledge termed constructivism, ${ }^{4}$ associated with the concept of social constructionism. ${ }^{10}$ Constructivism maintains that truth is a coconstructed phenomenon-"findings are literally the creation of the process of interaction between the inquirer and the inquired ... who become fused into a single (monist) entity." ${ }^{4}$ For example, gravity is a manifestation of the

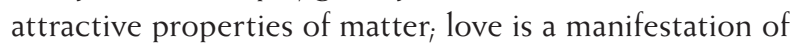
shared meaning between 2 people. These interactions have, not a realist, but a relativist ontology ${ }^{4}$ - true-tothose-involved. The ontological-epistemological distinction is obliterated in constructivism, because what is really there and the relation of the observer-participant to it are different versions of the same question. This approach uses such research methods as appreciative inquiry ${ }^{11}$ and participatory action research, ${ }^{12}$ which facilitate mutual learning, emergent understandings, and consensus. Validity requires that seemingly contradictory things make sense as a whole to the persons involved (termed crystallization of meaning) ${ }^{13}$

Constructivism reveals the cocreative nature of innovation. A genuinely new insight, by definition, has not yet been formed. Instead, it emerges through complex responsive processes. ${ }^{14}$ The result is not the property of one or another author, but a shared entwining that also has its own unique identity and properties. The idea of a photograph and the idea of radio waves both contributed to the idea of television. Two parents give life to a child. It may be possible to track connections between new and old, but the television and the child are different from the things that gave them birth and are genuinely new.

\section{Positivism, Critical Theory, and Constructivism Provide Complementary Insights Into Stories in Evolution}

I am putting forward the idea that theories are not truth as such but are lenses that filter certain elements from complex wholes. This concept is not new. As Heisenberg said: "What we observe is not nature itself, but nature exposed to our method of questioning." ${ }^{15}$ 
Different kinds of lenses or questions produce different kinds of truth or answers.

This type of filtering is what happens when we use our senses to "see" a garden. When I "look" at it with my ears, I hear bird song. If I "look" with my nose, I smell flower pollen. My eyes see colorful trees and bushes. My different senses filter from the fuller picture those aspects that resonate with the way I am looking.

I can look at a garden using the eyes of the 3 theories of knowledge described above. If I look with the eyes of positivism, I see what can be named and counted-birdsong, scent, and trees. If I look with the eyes of critical theory, I can see more hidden or interconnected truths - the effect of wind and the changing seasons on plant growth. If I look with the eyes of constructivism, I will see processes of creative interaction-bees pollinating flowers and birds building nests from whatever materials are available. Each insight is valuable, but none captures it all. Together the insights reveal a fuller, moving picture. The responsibility is mine to discern what meaning it has for me as a whole.

We also use these 3 theories when making decisions about how to act. When a bus is speeding toward me, I quickly jump out of the way, making a positivist prediction that the bus will harm me. When I wish to make a complicated journey, however, I will search the timetables of buses and trains for routes that were invisible at first sight to me (critical theory). During the journey I may change my mind about my destination as I experience the difficulties in getting there and the attractiveness of other opportunities that have opened up for me (constructivism).

Complexity theorists call these 3 theories simple, complicated, and complex. In complicated situations the best option must be puzzled out more than in simple ones, but a correct solution will still be waiting to be discovered. By contrast, complexity "arises from the interaction between the components of a system and its environment." ${ }^{16}$ Answers do not preexist and must be created through multiple adaptations of the related components. ${ }^{17}$

In general practice we often encounter complexity, for example when someone has several complaints. The best way forward involves lateral thinking (a combination of critical theory and constructivism). Evidence from the past (re-search $=$ searching again) contributes only in part to this forward-looking process (development $=$ growth or evolution). Kierkegaard reminds us that many people inappropriately conflate research and development. He said: "Most organizational theorists, as well as most philosophers, mistake the certainty of structures seen in hindsight for the emergent order that frames living forward. Neither group of scholars has come to grips with the fact that their conceptual understandings trail life and are of a different character than is living forward." ${ }^{18}$

Evidence carries with it an imprint of the context of its generation. We cannot assume that evidence will be meaningful in other contexts and to those who do not share that context. Evidence should be food for thought rather than an authority that cannot be challenged-evidence is a snapshot of more-complex stories-in-evolution.

It is within stories that different kinds of evidence can be integrated. Each person thinks of his or her life as an integrated whole story-what MacIntyre calls narrative unity. ${ }^{19}$ Communities likewise wish to share a coherent history. In health the integrity of the whole story is maintained. Diseases can challenge this integrity. Evidence must illuminate both.

\section{IMPLICATIONS FOR GENERALIST MEDICAL PRACTICE}

We consciously or unconsciously use these 3 theories of knowledge in the consulting room when diagnosing, listening, and reflecting:

When I have reason to consider meningitis, positivism is my dominant approach. I take care to identify the characteristic features. Conversely, when trying to understand how multiple illnesses affect someone, I will use open questions (as in critical theory) to listen to what the patient has to say. When there are many possible ways forward, I ask the patient to go away to reflect (as will I), agreeing to meet again to devise the best overall plan (constructivism).

When a patient has hypertension, I may review the scientific evidence (positivism), but then reason that the evidence is based on a study with subjects younger than the person in front of me; it may therefore not be relevant in this context," and I may accept a different blood pressure than the evidence suggests (critical theory). I may then ask what the patient's preferences and practical constraints are, devising a personalized plan (constructivism).

Knowing the 3 different kinds of knowledge helps me to be a better clinician. Rather than listening merely to detect signs of a particular diagnosis, critical theory leads me to hear what someone is struggling to say in his or her own terms. Constructivism leads me to reflect ideas and experiences against others (the meaining of the word reflection), searching for interesting connections. From this playful interaction emerge new ways forward that no one had considered at the outset.

Knowing the 3 different kinds of knowledge helps me as a researcher to use qualitative inquiry, first as a prelude to finding the best thing to measure, and then as a way to reveal the complex interconnections within seemingly 
simple situations. It reminds me to facilitate participation in research and audit by stakeholders in care pathways ${ }^{20}$ and whole systems, ${ }^{21}$ not merely to facilitate later compliance, but also to generate the most trustworthy evidence for that context. There are many examples of how these 3 approaches produce competent practitioners and managers as well as better primary health care. ${ }^{22}$

We can contribute to the advancement of these ideas by supporting the following stances:

A narrative-based approach to consulting can lead to patients thinking differently about their lives, which will improve their overall health. ${ }^{23}$ Listening and reflection in the consulting room should reinforce a practitioner's interpretations and facilitate a "meeting between experts, ${ }^{24}$ wherein each listens and shares perspectives, negotiating what should and should not require medical treatment.

A multimethod, transdisciplinary, participatory approach to research and audit should replace the current unbalanced focus on quantitative inquiries. ${ }^{25} \mathrm{We}$ should encourage complex interventions ${ }^{26}$ that allow patients to tell their own stories, ${ }^{27}$ and participatory inquiry $^{28,29}$ that builds learning communities. ${ }^{30}$

Learning and change are complex, multileveled activities that go beyond the learning of facts. ${ }^{31} \mathrm{~A}$ learning organization ${ }^{32}$ uses these 3 theories of knowledge by engaging in single-loop learning (positivism) that checks for errors, double-loop learning that reveals hidden forces (critical theory), and deutero-learning that generates new understandings from team learning (constructivism). ${ }^{31}$

To read or post commentaries in response to this article, see it online at http://www.annfammed.org/cgi/content/full/4/5/450.

Key words: Epistemology; paradigm, primary health care; ontology; methodology; theory

Submitted December 9, 2003; submitted, revised, December 21, 2005; accepted January 18, 2006.

This essay is based on Chapter 11 of Thomas P. Integrating Primary Health Care - Leading, Managing, Facilitating. Oxford: Radcliffe Publishing; 2006.22

Acknowledgments: For help in presenting the ideas in this paper I wish to thank John Horder, Peter Kinch, Will Miller, Mike Parker, Kurt Stange and the Annals reviewers.

\section{References}

1. Rosser WW. Application of evidence from randomised controlled trials to general practice. Lancet. 1999;353:661-664.

2. Rothwell PM. External validity of randomised controlled trials: "to whom do the results of this trial apply?" Lancet. 2005;365:82-93.

3. Griffiths F, Green E, Tsouroufli M. The nature of medical evidence and its inherent uncertainty for the clinical consultation: qualitative study. BMJ. 2005;330:511.

4. Guba E. The Paradigm Dialog. Newbury Park, Calif: Sage Publications; 1990.
5. Heath I. The Mystery of General Practice. London: Nuffield Provincial Hospitals Trust; 1995.

6. Crabtree B, Miller W. Clinical research - a multimethod typology and qualitative roadmap. In: Crabtree B, Miller W, eds. Doing Qualitative Research. Thousand Oaks, Calif: Sage Publications; 1999:3-30.

7. Yin RK. Case Study Research. Thousand Oaks, Calif: Sage Publications; 1994.

8. Wulff H, Pederson A, Rosenburg R. Philosophy of Medicine - An Introduction. Oxford: Blackwell; 1990.

9. Kincheloe JL, McLaren P. Rethinking critical theory and qualitative research. In: Denzin N, Lincoln Y, eds. Handbook of Qualitative Research. Thousand Oaks, Calif: Sage Publications; 2000:Chapter 10.

10. Shotter J. Conversational Realities - Constructing Life Through Language. London: Sage Publications; 2000.

11. Whitney D, Trosten-Bloom A. The Power of Appreciative Inquiry. San Francisco, Calif: Berrett-Koehler; 2003.

12. Whyte WF. Participatory Action Research. New York, NY: Sage Publications; 1991.

13. Janesick VJ. The choreography of qualitative research design. In: Denzin N, Lincoln Y, eds. Handbook of Qualitative Research. Thousand Oaks, Calif: Sage Publications; 2000:Chapter 13.

14. Stacey R. Complex Responsive Processes in Organizations. London: Routledge; 2001.

15. Capra F. The Web of Life. London: Flamingo; 1997.

16. Hassey A. Complexity and the clinical encounter. In: Sweeney K, Griffiths F, eds. Complexity and Healthcare - An Introduction. Abingdon: Radcliffe Medical Press; 2002:59-74.

17. Plsek $P$. Redesigning health care with insights from the science of complex adaptive systems. In: Crossing the Quality Chasm - A New Health System for the 21st Century. Hyattsville, Md: National Academy Press; 2000:309-322.

18. Weick KE. That's moving: theories that matter. J Management Inq. 1999;8:134-142.

19. MacIntyre A. After Virtue. London: Duckworth; 2000.

20. Thomas $P$, Oni L, Alli M, et al. Antenatal screening for haemoglobinopathies in primary care: a whole system participatory action research project. Br J Gen Pract. 2005;55:424-428.

21. Thomas P, McDonnell J, McCulloch J, et al. Increasing capacity for innovation in bureaucratic primary care organizations: a whole system participatory action research project. Ann Fam Med. 2005;3:312-317.

22. Thomas P. Integrating Primary Health Care - Leading, Managing, Facilitating. Oxford: Radcliffe Publishing; 2006.

23. Launer J. Narrative-based Primary Care. A Practical Guide. Oxford: Radcliffe Medical Press; 2002.

24. Tuckett D, Boulton M, Olson C, Williams A. Meetings Between Experts. London: Tavistock; 1985.

25. Stange KC, Miller WL, MCWhinney I. Developing the knowledge base of family practice. Fam Med. 2001;33:286-297.

26. Campbell M, Fitzpatrick $R$, Haines $A$, et al. Framework for design and evaluation of complex interventions to improve health. BMJ. 2000;321:694-696.

27. Greenhalgh T, Collard A, Begum N. Sharing stories: complex intervention for diabetes education in minority ethnic groups who do not speak English. BMJ. 2005;330:628.

28. Macaulay AC, Commanda LE, Freeman WL, et al. Participatory research maximises community and lay involvement. North American Primary Care Research Group. BMJ. 1999;319:774-778.

29. Reason P. Three approaches to participative inquiry. In: Denzin N, Lincoln Y, eds. Handbook of Qualitative Research. Thousand Oaks, Calif: Sage Publications; 1994:Chapter 20.

30. Wenger E. Communities of practice and social learning systems. Organization. 2000;7:225-246.

31. Argyris C, Schon DA. Organizational Learning 2 - Theory, Method and Practice. Boston, Mass: Addison Wesley; 1996.

32. Senge P. The Fifth Discipline. London: Century Hutchinson; 1993. 